\title{
DA MODERNIDADE EM LUC FERRY À PÓS-MODERNIDADE DE VATTIMO: AS DIFERENTES CONCEPÇÕES DE NIILISMO
}

\author{
Douglas Willian Ferreira ${ }^{1}$ \\ Universidade Federal de Juiz de Fora (UFJF) \\ (iD) https://orcid.org/0000-0002-6190-6370 \\ E-mail: douglasinvictus@hotmail.com
}

\section{RESUMO:}

$O$ referido trabalho pretende estabelecer uma interpretação acerca da modernidade e da passagem dessa à pós-modernidade a partir da filosofia de dois autores contemporâneos, a saber, o filósofo francês Luc Ferry e o filósofo italiano Gianni Vattimo. Notar-se-á que entre os autores, apesar de alguns poucos pontos em comum, prevalece divergência de pontos de vista e de compreensão dos acontecimentos históricos, políticos e sociais que marcaram a sociedade moderna e, posteriormente, a pós-modernidade. A chave de leitura será o conceito de niilismo, que em Ferry ganha uma conotação de força e de manutenção de verdades fortes, o que caracteriza, segundo ele, a modernidade; enquanto que, em Vattimo esse niilismo é o enfraquecimento dessas estruturas modernas e a garantia da pósmodernidade enquanto um momento de superação das verdades metafísicas. Diante desse cenário, analisaremos os limites da proposta de Ferry que se apega a uma crítica do niilismo realizada por Nietzsche, desconsiderando, contudo, a afirmação que o anunciador da morte de Deus faz de um niilismo ativo.

PALAVRAS-CHAVE: Modernidade; Pós-modernidade; Niilismo.

\section{FROM MODERNITY IN LUC FERRY TO VATTIMO'S POSTMODERNITY: THE DIFFERENT CONCEPTIONS OF NIHILISM}

\begin{abstract}
:
This study intends to show an interpretation about modernity and the transition from this to postmodernity based on the philosophy of two contemporary authors, namely the French philosopher Luc Ferry and the Italian philosopher Gianni Vattimo. It will be observed that among the authors, despite a few points in common, there is a difference of views and understanding of the historical, political and societal issues that marked modern society and, later, postmodernity. The key to reading will be the concept of nihilism, which in Ferry gains a connotation of strength and maintenance of hard truths, which, according to him, characterizes modernity; while in Vattimo this nihilism is the breaking of these modern structures and the guarantee of postmodernity as a moment of overcoming metaphysical truths. In sight of this scenario, we will examine the limits of the proposal of Ferry that is bound to a criticism of the nihilism realized by Nietzsche, disregarding, however, the statement that the announcer of the death of God does of an active nihilism.
\end{abstract}

KEYWORDS: Modernity; Postmodernity; Nihilism.

\footnotetext{
${ }^{1}$ Doutorando em Ciências da Religião e professor substituto na Universidade Federal de Juiz de Fora (UFJF), Juiz de Fora - MG, Brasil. . Bolsista do(a): Coordenação de Aperfeiçoamento de Pessoal de Nível Superior, CAPES, Brasil..
}

FERREIRA, Douglas Willian. Da modernidade em Luc Ferry à pós-modernidade de Vattimo: as diferentes concepções de niilismo. Griot : Revista de Filosofia, Amargosa - BA, v.19, n.2, p.87-107, junho, 2019. 


\section{Introdução}

Para compreender a situação niilista da pós-modernidade devemos, didaticamente, partir de uma concepção de modernidade para então entender a superação desse momento histórico-filosófico, e chegarmos a uma formulação desse niilismo que circunscreve a realidade do mundo ${ }^{2}$ e atualidade do pensamento filosófico. Para tal, conceberemos a modernidade sob o prisma do humanismo de Luc Ferry sem, contudo, deixar de apresentar a compreensão que Vattimo possui da mesma. De modo geral, ao expor o pensamento moderno, já se tornará evidente o niilismo no pensamento de Ferry, uma vez que niilismo e modernidade são, para ele, sinônimos. Contudo, é necessário dar um passo adiante na interpretação de Ferry, apontando outros aspectos niilistas de sua filosofia que não aqueles que se caracterizam com a tipicidade da modernidade. Nesse sentido é que Vattimo entra em cena: o filósofo italiano permite compreender a pós-modernidade como superação do pensamento moderno, não como um abandono de tudo aquilo que até então fora produzido, mas como uma distorção da proposta filosófica moderna. A partir disso, a situação niilista da pós-modernidade se torna mais evidente, não somente em Vattimo, mas também em Ferry, como algo que constitui a própria vivência do homem pós-moderno. Reconhecendo esse caráter constitutivo do ser humano, o niilismo deixa então de ser um problema a se superar e se torna uma realidade contextual do acontecer da vida.

\section{Os fundamentos da modernidade: o sujeito autoconsciente e o progresso}

Considerar o niilismo como uma característica da pós-modernidade requer, primeiramente, uma compreensão daquilo que se caracteriza como moderno, ou seja, é necessário um retorno histórico-filosófico à forma de pensar e compreender a modernidade, para posteriormente, analisar o papel do niilismo na constituição da condição do "pós" tratada pelos autores que essa tese se põe a investigar. Nesse sentido, a compreensão que aqui se dará sobre a modernidade estará ancorada, sobretudo, nas interpretações do filósofo agnóstico Luc Ferry acerca dessa modernidade, enquanto que a pós-modernidade será tratada a partir da proposta do filósofo cristão italiano Gianni Vattimo ${ }^{3}$.

Ferry compreende a modernidade como um momento de propagação de fortes ideais, de luta por verdades transcendentes, que muitas vezes levavam o homem moderno à cegueira. Isso porque o ser humano estava tomado pelas ideologias e por suas fortes crenças, por utopias laicas que queriam afirmar o princípio de toda verdade no próprio homem. (FERRY, 2004, p. 50). É certo que, essa crença no

\footnotetext{
2 A realidade do mundo é aplicada aqui, segundo Vattimo, como "alguma coisa que se constitui como contexto, das múltiplas fabulações" (VATTIMO, 1992, p. 32), ou seja, o espaço atual em que se torna possível o debate filosófico, sobretudo, a apresentação dos diversos pontos de vista, não tidas como verdades absolutas.

3 As adjetivações dadas aqui aos autores que serão trabalhados na tese visam enfatizar uma grande diferença entre os dois autores: de um lado temos o pensamento laico do filósofo francês que se declara agnóstico (em alguns momentos Ferry se declara ateu) e que tenta, a todo custo, se distanciar da religião; de outro, tem-se o pensamento de Vattimo, um filósofo cristão, que apresenta os aspectos cristãos da secularização. Em que medida os dois se distanciam e se aproximam é um interesse de nossa tese, porém, o que mais nos interessa é notar a convergência do pensamento de Ferry com Vattimo na compreensão da secularização como um acontecimento marcadamente cristão, fato negado por Ferry, mas não por sua construção filosófica.
}

FERREIRA, Douglas Willian. Da modernidade em Luc Ferry à pós-modernidade de Vattimo: as diferentes concepções de niilismo. Griot : Revista de Filosofia, Amargosa - BA, v.19, n.2, p.87-107, junho, 2019. 
humano, que tentava superar as crenças religiosas, o seguimento cego à fé e aos dogmas que por séculos, haviam embasado não somente a estrutura religiosa medieval, mas também a cultura, o pensamento, a sociedade e a economia europeia, fracassou. Surgia a crença no próprio do homem, a saber, sua racionalidade e liberdade (FERRY, 2012a, p. 146-149). O Iluminismo não permitia mais um seguimento acrítico aos ditames religiosos, uma vez que o fato de o ser humano ser livre é a condição de possibilidade do laicismo, "se o Homem não se define mais por seu pertencimento a uma comunidade religiosa, se está, por assim dizer, além, [...] então lhe é permitido o distanciamento em relação à religião" (FERRY, 2012a, p. 173). Note-se bem que, Ferry coloca o termo 'Homem' com letra maiúscula, destacando esse caráter central adquirido por ele a partir da grande Declaração dos direitos do Homem e do Cidadão de 1789. Sendo assim, uma análise dessa modernidade iluminista, nos moldes de Ferry, constata que a razão dava a esperança de novos tempos: afirmação da liberdade, valorização do humano e a superação dos fundamentos divinos. A razão desbancou a fé, e a verdade parecia se tornar cada vez mais acessível e humanizada. Trata-se de um tempo convicto do domínio do futuro, que segundo Habermas, "indica a época orientada para o futuro, que está aberta ao novo que há de vir" (HABERMAS, 2000, p. 9). Ou seja, a modernidade é o momento em que "o progresso se coagula, tornando-se norma histórica" (HABERMAS, 2000, p. 20), de modo que o progresso se torna regra, porque o desenvolvimento tecnológico e científico resultado da supervalorização da capacidade racional humana impulsiona esse mesmo homem ao desejo de aperfeiçoamento e domínio.

O progresso é uma das tantas crenças da modernidade, e com ele "as capacidades humanas de dispor tecnicamente da natureza se intensificaram, e continuam intensificando-se" (VATTIMO, 2002, p. XII) de uma maneira tal que esse ideal parece vazio, posto que infindavelmente permanece necessitado de progredir. Contudo, há uma subjetividade ${ }^{4}$ por trás dessa incessante busca. E essa subjetividade resulta de certos acontecimentos inaugurais da modernidade, como o já citado Iluminismo, a Reforma religiosa, a Revolução Francesa, o Descobrimento do Novo Mundo e etc.

Com Lutero, a fé religiosa tornou-se reflexiva; na solidão da subjetividade, o mundo divino se transformou em algo posto por nós. Contra a fé na autoridade da predicação e da tradição, o protestantismo afirma a soberania do sujeito que faz valer seu discernimento: a hóstia não é mais que farinha, as relíquias não são mais que ossos. Depois, a declaração dos Direitos do Homem e o Código Napoleônico realçaram o princípio da liberdade da vontade como o fundamento substancial do Estado, em detrimento do direito histórico (HABERMAS, 2000, p. 26).

\footnotetext{
4 A subjetividade se torna o princípio da modernidade. Segundo Habermas, Hegel vê a subjetividade como estrutura do mundo moderno. "valendo-se desse princípio explica simultaneamente a superioridade do mundo moderno e sua tendência à crise[...]. O princípio do mundo moderno é em geral a liberdade da subjetividade, princípio segundo o qual todos os aspectos essenciais presentes na totalidade espiritual se desenvolvem para alcançar o seu direito" (HABERMAS, 2000, p. 25). De outro modo, essa subjetividade é marcada por um sujeito que é consciente de si, pois, "com a consciência de si, entramos, pois, na terra pátria da verdade!" (HEGEL, 1992, p. 120), dessa verdade como absoluto que caracteriza a própria modernidade.
} 
Assim, superou-se o fundamento religioso dos direitos do homem, que até então, se pautavam nos mandamentos divinos, e era imposto de fora, como um sufocamento à subjetividade. Agora, o princípio da subjetividade encontra sua liberdade sob o respaldo de uma razão que leva o homem a passos largos para o progresso, o que Ferry compreende, de certo modo, a partir do conceito de perfectibilidade de Rousseau.

Segundo o autor, "Rousseau designa essa liberdade pelo nome de 'perfectibilidade', pois é ela que por assim dizer vai ser o novo motor de uma história de que não somos prisioneiros, mas que nós mesmos inventamos livremente" (FERRY, 2008b, p. 55), uma história de aperfeiçoamento. $\mathrm{O}$ fato de o homem se tornar reflexivo, não fecha para ele o mundo externo, porque não se trata de um movimento místico de interiorização e experiência da solidão. $O$ reconhecimento de uma subjetividade pensante é, sobretudo, um movimento de saída dos fundamentos e de descoberta dos limites. Porém, essa subjetividade que ajudaria a ultrapassar os domínios fundamentais da tradição e da fé não é ainda, aquela subjetividade, de acordo com Vattimo, em sua obra Ética da interpretação, que "se anuncia sobretudo como desmascaramento da superficialidade da consciência" (VATTIMO, 1991, p. $121)^{5}$.

Do contrário, somente um sujeito, altamente consciente, seria capaz de tantas transformações em um curto espaço de tempo. Soma-se a todos esses acontecimentos históricos o nascimento do Racionalismo Cartesiano e sua valorização do Cogito que "inaugura uma nova época: a do humanismo moderno, no seio do qual vai reinar o que será designado "subjetividade" (FERRY, 2007, p. 158). Com o racionalismo, tem-se evidenciada não somente uma nova definição da verdade, mas também um critério novo de alcance dessa verdade. Há um rompimento com toda a forma de conhecimento de até então, uma rejeição de todas as crenças herdadas da tradição, uma vez que a verdade perde seu caráter religioso e divino. A verdade está ao alcance da razão humana, e a subjetividade é "o critério mais seguro da verdade" (FERRY, 2007, p. 159). A modernidade é revolucionária, porque, segundo Ferry, ela

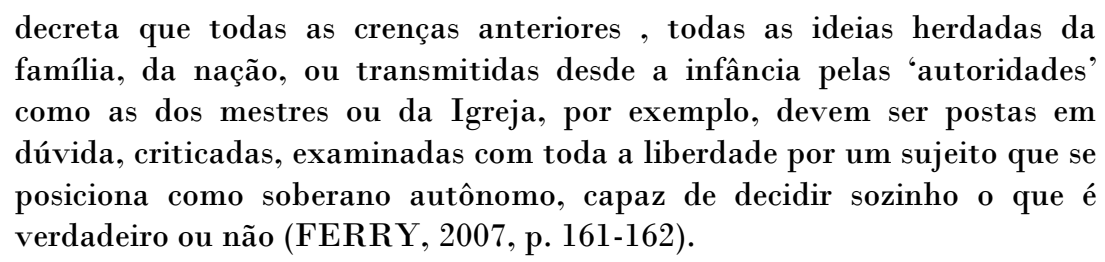

Disso decorre, poder ser tratado aqui três aspectos, que a nosso ver, envolvem a compreensão da modernidade nesses autores: a subjetividade, o progresso e a crítica à tradiçãa ${ }^{6}$. De pronto, se percebe distinções entre os dois filósofos quanto a esses temas: Ferry tende a defender a modernidade como um momento revolucionário, em que se faz necessário romper com a tradição e sua filiação religiosa. Vattimo, contudo, defende o caráter de continuidade dessa modernidade,

\footnotetext{
5 Texto original: "se anuncia sobre todo como desenmascaramiento de la superficialidad de la consciencia" (VATTIMO, 1991, p. 121 - tradução nossa).

6 Nesse ponto trataremos somente da questão relacionada ao modo como os autores caracterizam a subjetividade como fundamento da modernidade.
} 
mas isso não significa que ele não conceda a ela algo de novidadeiro. No âmbito da subjetividade, ambos os autores, reconhecem sua centralidade enquanto justificativa das ações e do conhecimento do homem moderno: ou através do racionalismo cartesiano, ou como fundamento das experiências sensíveis dos empiristas. Desse modo, a compreensão do mundo se dá a partir de um sujeito que o ordena, decifra-o e o experiencia cotidianamente. A subjetividade consciente, afirmará Vattimo, aponta para a noção de verdade e do ser como fundamento, características primárias da modernidade (VATTIMO, 1991, p. 122-123). Orientado pela filosofia de Nietzsche, o autor afirma que essa subjetividade desde Sócrates, com sua forma definida e racional, marca a atitude apolínea, que vai contra a vida e as pulsões (VATTIMO, 1991, p. 121). Essa é, caracteristicamente, a atitude de uma subjetividade que se põe como autônoma, capaz de se tornar o termômetro do que é ou não verdadeiro em que o programa de emancipação iluminista reivindica, juntamente com a liberdade, a "consciência de que uma sociedade livre é aquela em que o homem pode se tornar consciente de si numa 'esfera pública', a da opinião pública, da livre discussão, etc., não ofuscada por dogmas, preconceitos, superstições" (VATTIMO, 1992, p.25).

\section{Da consciência do sujeito à afirmação da liberdade}

Essa consciência de si que caracteriza a própria vida social, segundo Ferry, é claramente resultada da razão humana, posto que "é o homem, o sujeito humano, que se torna o fundamento de todos os pensamentos e de todos os projetos" (FERRY, 2007, p. 162). O sujeito encontra na razão a estrutura da vivência livre. Não se pode mais viver subjugado pela cegueira dogmática de instituições religiosas e políticas que visam, dentre outras coisas, dominar o homem. A autonomia garantida pela razão é o trampolim para a superação da tradição e seus imperativos, "não convém 'dar crédito', como diz Descartes, senão àquilo de que podemos estar absolutamente certos por nós mesmos" (FERRY, 2007, p. 163). E essa consciência individual impõe uma certeza maior que todas as outras: a de um sujeito que se torna o dominador e manipulador do mundo. Esse sujeito é, portanto, livre, e a liberdade não se limita ao âmbito do conhecimento e da independência em relação às crenças. Ela tem um viés de praticidade, porque exige rompimentos com as antigas formas de agir. A subjetividade tem de ser afirmada nas práticas morais e no domínio do mundo, porque a natureza é um sistema de leis codificados, determinados e reconhecidos pelo homem. As novas ciências e os novos métodos científicos dão ao homem um falso sentimento de se sentir em casa: ele organiza, define, ordena, cria regras e especifica o mundo natural, julga, hierarquiza, e estabelece relações de poder no mundo social. Diante disso, tudo aquilo que até então era dado como verdade divina passa a ser questionado e superado.

Contudo, essa percepção da modernidade como um desligamento das normas da tradição não é uma interpretação exclusiva de Ferry. Nesse seu ponto de vista, tem-se muito a influência do pensamento de Hegel que, segundo Habermas, teria sido o primeiro a tomar como problema filosófico "o processo pelo qual a modernidade se desliga das sugestões normativas do passado" (HABERMAS, 2000, p. 24). Inclusive, Hegel é o primeiro a apontar essa subjetividade como o princípio dos novos tempos. A inquietude resultada das cisões da modernidade desperta na 
modernidade a necessidade de uma auto certificação, de modo a fazer da superioridade da modernidade sua tendência à crise. Habermas, nessa análise do discurso filosófico da modernidade é enfático: "a primeira tentativa de levar a modernidade ao nível do conceito é originariamente uma crítica da modernidade" (2000, p. 25). E Ferry se torna um herdeiro desse modo hegeliano de ler o moderno, na medida em que enfatiza tantos rompimentos como algo sui generis da filosofia moderna.

Consequentemente, essas transformações filosóficas e epistemológicas levaram a uma evidente mudança dos princípios morais, e, segundo Ferry em Famílias amo vocês (2008a), da vivência da intimidade, como também da vida política. A moral moderna, por um lado, se pauta "no direito do indivíduo de discernir como válido o que ele deve fazer; por outro, funda-se na exigência de que cada um persiga os fins do bem-estar particular em consonância com o bem-estar de todos os outros" (HABERMAS, 2000, p. 27). Convém ressaltar, portanto, que o próprio homem se torna a medida do certo e do errado, do justo e do injusto, do bem e do mal. Sua capacidade de discernimento, resultada do uso que faz livremente da razão, confere validade e direito às suas atitudes. Vale lembrar, contudo, que o bemestar procurado pelo homem não pode estar em desacordo com o bem coletivo. Essa nova moral, não-religiosa nem teísta, mas leiga, se define por "um conjunto de valores expressos por deveres ou imperativos que nos pedem um mínimo de respeito pelo outro, sem o qual uma vida comum pacificada é impossível" (FERRY, 2007, p. 165). Daí o respeito à dignidade e à liberdade do homem que apontam para o fato de que essa preocupação com o coletivo não é uma novidade formulada pela racionalidade desse sujeito moderno, uma tal leitura seria reducionista. Há que se considerar a desmistificação da moral, contudo, acentuar que "muitos dos valores cristãos parecem hoje mais populares do que outrora: existe uma reprovação geral do racismo, propaga-se um humanitarismo que recusa a ideia da guerra, que se comove com a miséria do terceiro mundo, que invoca a paz e a solidariedade" (VATTIMO, 1998, p. 50). Ou seja, o caráter novidadeiro e de rompimento, que Ferry muitas vezes apresenta como característico dessa modernidade, apresenta-se, também, como continuidade, em muitos aspectos, remodelada, da tradição.

Somado a essas transformações empreendidas na modernidade e apontadas pelos autores contemporâneos, Ferry dá sua contribuição e investiga a substancial mudança acontecida na vida íntima e no casamento ${ }^{7}$. O homem moderno, motivado pela liberdade, faz suas escolhas, e rompe com a sociedade tradicional, momento em que o casamento não se origina da paixão amorosa e do sentimento, mas atende a finalidades e imperativos de conveniência (FERRY, 2012a, p.77). Os princípios tradicionais asseguravam os matrimônios arranjados no intuito de manter a linhagem ou somar riquezas. Todavia, o sujeito moderno, responsável por suas escolhas, desfaz com essa lógica de um matrimônio arranjado, fazendo surgir o casamento por amor como uma nova forma de união. Ademais, essa nova estrutura

\footnotetext{
7 A tese acerca da qual a intimidade e o casamento por amor marcam o processo de secularização e enfraquecimento das verdades modernas é defendida por Ferry a partir das contribuições dos historiadores François Lebrun, especialmente na obra A vida conjugal no Antigo Regime (1998), Jean-Luis Flandrin na obra Famílias, parentesco, casa, sexualidade na sociedade antiga (1976) e Philippe Ariès com sua obra A criança e a vida familiar no Antigo regime (1973). Essa influência é notada sobretudo nas obras Famílias, amo vocês (2010), especificamente no capítulo III e $A$ revolução do amor (2012a).
} 
da vida matrimonial resulta no surgimento da vida privada, uma vez que até então, nas sociedades tradicionais, "a comunidade se permitia intervir na vida familiar de uma maneira que nos pareceria hoje inconcebível” (FERRY, 2008a, p. 102). Assim, homens e mulheres optam pelo anonimato dos grandes centros ao invés de ficarem presos à sua comunidade de origem, onde acentuadamente, a família e o líder religioso e, sutilmente, os demais membros da comunidade, interferiam nas decisões da vida íntima e nas relações e vínculos criados pelo sujeito, oprimindo-o com seus tradicionais valores e forçando-o a se comportar segundo as regras da comunidade. Desse modo, a modernidade é rompimento com a submissão familiar e comunitária, uma vez que o sujeito conquista sua liberdade de escolha quando deixa a casa de seus pais e também a liberdade financeira, quando sai dos vilarejos para trabalhar nos grandes centros.

\section{Uma modernidade violenta: a força metafísica da política}

Não menos importantes são as mudanças e os acontecimentos políticos decorridos das transformações empreendidas na modernidade. O Colonialismo e o Imperialismo revelam uma das faces apavorantes dessas alterações políticas advindas da supervalorização do sujeito racional, aqui, sinônimo de homem civilizado ou europeu. Além disso, novas formas de ordenamento político se tornaram vigentes: de um lado, a democracia e o republicanismo demoliam os governos absolutos dos reis, e prometiam ser possível ao homem construir e conduzir sua história pela 'magia do sufrágio universal'; de outro, o socialismo e o comunismo se erguiam fortemente contra o crescente republicanismo, movido pela busca da igualdade social e pela redistribuição justa dos bens materiais. Ambos, porém, se pautavam no desejo de fazer a política progredir, colocando-a como uma orientação ao futuro. Nessa luta, o resultado também não foi motivador, uma vez que duas guerras mundiais aconteceram como resultado dessa batalha ideológica e de domínio.

Ao que se vê, a modernidade carregou consigo muitos ideais fortes, destrutivos e violentos. Cada qual, justificado pelo sujeito racional, pretendia o domínio e a submissão de povos e culturas inteiras. A Europa se colocou como o modelo de civilização a ser seguido, o berço da racionalidade e o lugar de reconhecimento da supremacia humana, "é como dizer: nós europeus somos a melhor forma de humanidade, todo o curso da história se ordena conforme realize mais ou menos completamente esse ideal" (VATTIMO, 1992, p. 10). E o homem se tornou o senhor da técnica e do progresso. As mudanças eram constantes e a novidade era rotineira, pois os homens de ciência e os intelectuais não se satisfaziam com o já dado. $\mathrm{O}$ frenesi das novas descobertas promovia o desejo de rompimento com toda a cultura anterior, porque ser moderno é não olhar para trás, mas para frente. E o progresso trouxe em seu bojo um desenfreado desejo de inovação. Com isso, a própria concepção de história e de historicidade perdem sentido.

\footnotetext{
A transitoriedade das coisas dificulta a preservação de todo sentido de continuidade histórica. Se há algum sentido na história, há que descobri-lo e defini-lo a partir de dentro do turbilhão da mudança. Um turbilhão que afeta tanto os termos da discussão como o que está sendo discutido. A modernidade, por conseguinte, não apenas envolve uma implacável
} 
ruptura com todas e quaisquer condições históricas precedentes, como é caracterizada por um interminável processo de rupturas e fragmentações internas inerentes (HARVEY, 1992, p. 22).

Desse modo, a modernidade é fugidia, e quer superar de todas as formas tudo aquilo que até então já havia sido produzido no âmbito do conhecimento, da política, da moral e etc. Essa fragmentação e contingência, contudo, não evidencia uma sua fraqueza. Ao contrário, são muitas certezas a se digladiarem, querendo se impor e se tornar paradigma, de tal modo que, nem mesmo o passado é respeitado. A transitoriedade dificulta o reconhecimento da continuidade histórica, uma vez que o apelo ao novo e ao original "se liga a uma perspectiva mais geral que, como sucede na época do Iluminismo, considera a história humana como um progressivo processo de emancipação" resultando na impossibilidade de se "falar da história como qualquer coisa de unitário" (VATTIMO, 1992, p. 8). Esse progresso rotineiro transforma a concepção de história do cristianismo ${ }^{8}$. Assim, a secularização não se restringe ao campo político, mas ganha espaço em outras dimensões da vida humana. A modernidade é a história do progresso, e isso pode ser lido nas entrelinhas das mudanças que ela propiciou, superando a ideia cristã da história como história da salvação. Segundo Vattimo, "a história que, a visão cristã, se apresentava como história da salvação tornou-se, primeiramente, busca de uma condição de perfeição intramundana e, depois, progressivamente, história do progresso" (2002, p. XIII). Contudo, o ideal do progresso é vazio (VATTIMO, 2002, p. XIII), pois está sempre motivado por um novo progresso. Sua lógica é progredir por progredir. Isso é o que Vattimo quis apontar ao dizer que a modernidade é "a época em que se torna valor determinante o fato de ser moderno" (1992, p. 7). Esse lado sombrio, camuflado da modernidade, resultaria nas atrocidades do século XX.

A Europa mesma se deslumbrou com o alcance do desenvolvimento da racionalidade e perdeu o controle sobre o progresso. "O século $\mathrm{XX}$ - com seus campos de concentração e esquadrões da morte, seu militarismo e duas guerras mundiais, sua ameaça de aniquilação nuclear e sua experiência de Hiroshima e Nagasaki - certamente deitou por terra esse otimismo" (HARVEY, 1992, p. 23). Ao que se vê, os mais nobres ideais modernos acabaram por culminar nas maiores desumanidades e barbaridades. Esse foi o resultado da supervalorização do homem. Essa excessiva confiança no novo não teria sido tão dogmática e violenta quanto o próprio domínio da fé anteriormente à modernidade? A superação e o rompimento com o passado e suas verdades dogmáticas não teriam resultado em novos dogmatismos?

Esse é o risco que a modernidade não fora capaz de reconhecer: a superação, o progresso e rompimento com o passado, motivado pelo incessante desejo do novo, faz com que os erros do passado sejam novamente cometidos. Nesse sentido, a

\footnotetext{
${ }^{8} \mathrm{O}$ cristianismo entende a história como uma continuidade, em outros termos, como história da salvação. Essa história não teve seu fim com a vinda do filho de Deus, sua morte e ressurreição, mas continua a acontecer. Segundo Vattimo, "é a encarnação entendida como kênosis que se realiza hoje de modo mais pleno" (VATTIMO, 2016, p. 64), ou seja, a ideia de encarnação que está no centro da história da salvação impõe-se a nós hoje como "dissolução das razões do fundamentalismo" (VATTIMO, 2016, p. 65). Assim, "a história da salvação acontece ou se dá somente como história da interpretação" (VATTIMO, 2004, p. 76) e se torna especialmente visível nos acontecimentos da pós-modernidade. Contudo, esse enfraquecimento só se tornou possível a partir da continuidade do acontecer histórico, sem rupturas nem rompimentos.
} 
modernidade fora tão violenta quanto as implacáveis cruzadas medievais, e tão dominadora quanto a fé dogmática. A própria modernidade reafirmou, de uma maneira laica, os dogmatismos, as verdades supremas e as transcendências das quais queria se tornar independente. Rompendo com a tradição, os modernos foram incapazes de observar os erros do passado, repetindo-os. Desse modo, "a erosão das tradições, quaisquer que sejam suas eventuais consequências benéficas a longo prazo, tem o efeito imediato de suscitar angústia" (FERRY, 2010, p. 16) e de aniquilar sentido, uma vez que o sujeito fica desnorteado diante das tantas mudanças que efetivou. Diante disso, cabe questionar: Como acabar com essa angústia resultada do fim da tradição? Essa angústia, resultada do fim dos elementos niilistas da modernidade, para ser superada, não requer a construção de um novo niilismo? Mas quem ainda quer se subjugar a forças e pressupostos da tradição e da metafísica? É evidente que um novo tempo se delineia para o ser humano. Poderíamos chamar esse novo momento de pós-modernidade? Como compreendê-la? Para tal, tomaremos como instrutor o pensamento de Gianni Vattimo.

\section{O que é a Pós-modernidade?}

Tendo caracterizado a modernidade, enfaticamente a partir do pensamento de Ferry, torna-se necessário dar um passo, e entender a pós-modernidade como um acontecimento que enfraquece estruturas e supera fundamentos. Nessa empreitada a proposta filosófica de Vattimo é crucial, uma vez que esse autor lança um olhar débil ${ }^{9}$ sobre a modernidade. Diante do pensamento absoluto e supra terreno da modernidade, como escapar a essa realidade?

Por um momento fora analisada a compreensão que Luc Ferry tem da modernidade, caracterizando-a como um niilismo. Contudo, a proposta de Ferry parece ainda insuficiente, propensa a um retorno às estruturas da modernidade por dois principais motivos: primeiro, porque apresenta como fundamental a busca por uma vida boa, que no fundo, tem como pressuposto a existência de uma vida 'ideal' a ser buscada; segundo, porque coloca o amor como o novo fundamento de uma revolução que supera a modernidade. Mas, essa centralidade do amor proposta pelo autor francês, só fará sentido e conquistará o homem contemporâneo a partir do instante em que os conceitos, empregados por Ferry perdem o 'aparente' aspecto metafísico-transcendental. Para tal, uma nova configuração da realidade deve ser apresentada.

Vive-se hoje um momento designado como pós-modernidade uma vez que se multiplicaram vertiginosamente os mass media (VATTIMO, 1992, p. 12). Segundo Vattimo (1992), esse momento de proliferação dos mass media é o instante de intensificação da pluralidade posto que a ideia de uma realidade homogênea, apreendida por conceitos e transmitida como verdade perde espaço para a

\footnotetext{
9 Débil é sinônimo de fraco, ou seja, trata da proposta de pensamento enfraquecido elaborada por Vattimo. Segundo Zabala, "The history of political power in the West is nothing but a weakening of Strong structures of power: from absolute monarchy to the constitutional and democratic state, from the authoritarian biblical interpretation of the Church to the Bible of the people as translated by Luther. If 'interpreting' is nothing but a form of weakening the Strong structures of the presence of na object 'out there'(the 'real'), then the postmodern age is not only the age when the ethical dangers of this identification are recognized but also the age that marks the religious comeback of Chistianity" (ZABALA, 2007, p. 17).
} 
"contaminação das múltiplas imagens, interpretações, reconstruções que, em concorrência entre si ou, seja como for, sem qualquer coordenação central, os media distribuem" (VATTIMO, 1992, p. 13). Essa pós-modernidade, como compreendida nesse trabalho, não tem a pretensão de se colocar como uma novidade histórica, ou, como um instante superior à modernidade, porque se assim o fosse, estaria na lógica do progresso e da novidade que a modernidade mesma traz como sua característica.

O pós de pós moderno indica, com efeito, uma despedida da modernidade, que, na medida em que quer fugir das suas lógicas de desenvolvimento, ou seja, sobretudo da ideia da 'superação' crítica em direção a uma nova fundação, busca precisamente o que Nietzsche e Heidegger procuraram em sua peculiar relação 'crítica' com o pensamento ocidental (VATTIMO, 2002, p. VII).

Assim, Vattimo afirma que a pós-modernidade se relaciona com a modernidade como uma despedida. Essa despedida é um esforço de fazer diferente, mas tendo sempre em vista aquilo que a modernidade deixou como legado. É por isso que a ideia de rompimento não é plausível, uma vez que romper é postergar tudo aquilo que fora construído, inclusive os modos de organizar e hierarquizar o real. $\mathrm{O}$ rompimento não permite ter em vista os erros e acertos do passado, para a partir deles, ter capacidade de discernir entre o que permanece e o que já não se justifica mais. $\mathrm{O}$ simples fato de romper com a modernidade pode levar o homem a esquecerse dela e de suas atrocidades, ou seja, deixar para trás tudo aquilo que a modernidade representou, ou legá-la ao esquecimento de um modo proposital, por um simples desencargo de consciência, pode resultar numa sua repetição, seu retorno. Quando se despede, contudo, há sempre diante dos olhos aquilo do qual se está despedindo. Nesse sentido, a superação não pode ser uma negação, mas um retomardistorcer, um retorno que reinterpreta e relê a modernidade. Vattimo ainda aponta Nietzsche e Heidegger como autores que auxiliam nesse processo de despedida da modernidade uma vez que a partir do pensamento de ambos, e posteriormente será visto em detalhes essas peculiaridades, o fundamento passa a ser visto como evento, como aquilo que acontece no seu historicizar-se.

O pós-moderno não é uma novidade em relação ao moderno, mas "dissolução da categoria do novo, como experiência de 'fim da história', mais do que como apresentação de uma etapa diferente, mais evoluída ou mais retrógrada, não importa, da própria história" (VATTIMO, 2002, p. IX). Esse fim da história, contudo, não tem o sentido de uma catástrofe que colocaria fim à vida do homem, ou seja, não é um sinônimo de "fim do mundo ${ }^{10 "}$. Trata-se, contudo, de uma dissolução da "ideia de uma história como processo unitário" (VATTIMO, 2002, p. XI), ou seja, há um sentimento de imobilidade histórica diante da experiência rotineira do

\footnotetext{
10 Vattimo faz questão de enfatizar que sua teoria sobre o fim da história não é uma teoria apocalíptica que caracteriza, em muitos aspectos, algumas das formas de pensar a atualidade a partir do pessimismo que gira entorno de acontecimentos recentes como a corrida armamentista, os problemas ambientais e etc. Na obra Em que creem os que não creem? Umberto Eco aponta esse aspecto apocalípstico, que compreende o fim da história como sinônimo de fim do mundo, como sendo os "movimentos políticos e sociais, de cunho laico e até mesmo ateus, que pretendiam apressar violentamente o fim dos tempos não para dar realidade à Cidade de Deus, mas a uma nova Cidade Terrena" (2016, p. 14). O autor caracteriza esse pensamento do fim dos tempos como caracteristicamente "típico do mundo laico" uma vez que o mundo laico é, segundo ele, obcecado por essa ideia, mesmo que de uma forma velada (2016, p. 15).
} 
progresso impulsionado pela técnica e pelos meios de informação. Assim, cada vez mais em que evolui a capacidade tecnológica do homem, cada vez menos os resultados dos novos empreendimentos serão vistos como novos. Isso tudo, porque o progresso se tornou rotina e a história viu-se esvaziada de seu valor final. Daí o fim da história ser caracterizada como uma unidade racional, de domínio e propagação de verdades fortes. Com esse "fim da história", contudo, vê-se efetivar uma fragmentação da história, sua pluralidade, narrada e contada de modos distintos, pelos distintos povos. Não é mais verdadeira somente a narrativa e a intepretação histórica efetivada pelos europeus, ou pelos dominadores em relação aos dominados.

\begin{abstract}
Derrubada a ideia de uma realidade central da história, o mundo da comunicação generalizada explode como uma multiplicidade de racionalidades 'locais' - minorias étnicas, sexuais, religiosas, culturais ou estéticas - que tomam a palavra, finalmente já não silenciadas e reprimidas pela ideia de que só exista uma única forma de verdadeira humanidade a realizar, com prejuízo de todas as peculiaridades, de todas as caracterizações limitadas, efêmeras, contingentes (VATTIMO, 1992, p. 14-15).
\end{abstract}

Ou seja, a ideia de centralidade e de unidade, característica da modernidade, abre espaço para uma interpretação múltipla do mundo e, inclusive, para a emergência de uma sociedade de comunicação, proliferada cada vez mais pelos mass media, porque acontece, para dizer em termos vattimianos, um desenraizamento dos dialetos locais (VATTIMO, 1992). Nesse contexto é que surge aquela forma de pensamento fraco "doravante identificado como pensiero debole - [...] um tipo de pensamento que significa tanto uma ideia do pensamento mais consciente dos seus limites [...], mas sobretudo uma teoria do debilitamento como traço constitutivo do ser" (ROCHA, 2013, p. 138), ou seja, uma forma de filosofar que sabe da impossibilidade de se universalizar, uma vez que fala em um determinado contexto e por ele é influenciado. Essa derrubada de uma compreensão da história como unitária é também sabedora de sua provisoriedade: nada pode ser imutável e eterno num mundo de contingências.

Esse fim da história, como se vê, traz em si a própria ideia de 'fim da verdadefundamento'. No fundo, é essa concepção moderna de verdade e de fundamento que Vattimo denuncia e reconhece ser necessário superar. Porém, parece espantoso que a multiplicidade, a efemeridade e a fragmentação, apresentadas como características da modernidade, permaneçam sob a forma do pensamento fraco, através da pluralidade. Com isso, não estaria o pensamento pós-moderno repetindo a modernidade? A superação buscada na pluralidade não promoveria ainda mais uma forma de pensamento moderno? Segundo a análise de David Harvey, o que diferencia a efemeridade dos modernos com a pluralidade da pós-modernidade é que essa não tenta transcender o caráter fragmentário e múltiplo, nem quer se opor a ele (HARVEY, 1992, p. 49). Ou seja, ao invés de apresentar sempre novas teorias que querem sobrepor-se às anteriores, rompendo com os antigos paradigmas, como fez a modernidade, o pensamento fraco é aquele que reconhece a possibilidade dessa fragmentação, e inclusive, a necessidade de se viver nessa condição, uma vez que não pretende criar verdades e teorias, visões de mundo e interpretações cada vez mais superiores às demais. A pós-modernidade assume essa efemeridade como constitutiva 
de si mesma. Esse é, inclusive, o modo com que a pós-modernidade pode olhar para si criticamente, assumindo sua transitoriedade. Esse ultrapassamento da situação moderna é aquilo que Heidegger chamará de superação da metafísica, e Nietzsche caracterizará como sendo a morte de Deus.

\section{A relação entre niilismo e modernidade em Ferry}

Essas distinções entre modernidade e pós-modernidade, fazem-se necessárias a fim de que seja melhor compreendido o que Ferry e Vattimo entendem como niilismo, uma vez que, o sentido dado ao termo está intimamente ligado à compreensão que ambos os autores possuem desses momentos histórico-filosóficos. Primeiramente, verificaremos a compreensão de niilismo de Luc Ferry. Vale lembrar que o autor apontou para o fato de que com o fim das estruturas tradicionais e metafísicas o homem se encontraria numa situação de angústia diante da falta de sentido. Essa falta de orientação é aquilo que muitos autores contemporâneos chamaram de niilismo. Em sua obra $O$ niilismo (1999), Volpi faz uma análise acerca desse conceito e as múltiplas conotações dadas a ele por diversos pensadores. Nessa dissecação do conceito, Volpi afirma que "o niilismo constitui, assim, uma situação de desnorteamento provocado pela falta de referências tradicionais, ou seja, dos valores e ideais que representavam uma resposta aos porquês e, como tais, iluminavam a caminhada humana" (1999, p. 8). Desse modo, inclusive, é que Ferry, compreende a modernidade como sendo o momento em que o niilismo acontece e se desenvolve com mais força. Diante do excesso de sentido encontra-se a falta de sentido. O homem moderno está deslumbrado com tanta novidade, mas essas, parecem ter deslocado o homem de seu eixo, porque o desconhecido parece tomá-lo. Essa situação, aparentemente desconfortável sobrepõe a verdade e a força da razão à própria liberdade, ou seja, não é necessário ao homem fazer escolhas, as coisas já estão dadas, as convicções já estão prontas, cabe ao homem segui-las. Ferry afirma, inclusive, que essa era a interpretação que Nietzsche dava do niilismo:

Em Nietzsche [...] o niilismo é justamente aquilo que está carregado de convicções fortes e nitidamente morais. É aquele que possui valores transcendentes, ideais superiores, quaisquer que eles sejam - religiosos, metafísicos ou leigos, humanistas ou materialistas, pouco importa. Por que empregar esse termo, cuja raiz latina remete à ideia de nihil, nada, de não existência? Simplesmente porque para Nietzsche, os ideais, todos os 'ídolos', como ele os chama, trazem a estrutura metafísico-religiosa do além, oposto a este mundo, do céu, sempre usado para 'destruir' a Terra e lançar sobre ela um olhar negativo. Isto é, os valores transcendentes e provedores de sentido, dos quais Nietzsche anuncia o crepúsculo e o fim próximo ('a morte de Deus'), são inventados pelos humanos para dar um significado à vida, para se consolar de sua dureza, logo, em muitos aspectos, para recusá-la tal como ela é, quer dizer, para negá-la (FERRY, 2012a, p. 182).

Desse modo, o nada que estrutura a própria ideia de niilismo é a negação da vida diante de tantas verdades estabelecidas. $O$ racionalismo com seu enaltecimento da razão, o empirismo e a valorização das experiências, a ciência e a autoconfiança em seus poderes de domínio e organização do mundo, o humanismo e sua exacerbada 
evidenciação do homem são também niilistas na medida em que remetem sempre o homem para uma outra realidade, mais perfeita que essa, na qual a vida mais uma vez é negada. Ou seja, o homem da ciência com suas experiências e teorias está sempre remetido para uma realidade diferente dessa, no intuito de aperfeiçoar a realidade presente, fazê-la distinta do que é. Essa vida cotidiana, banal, cheia de desafios e escolhas, de sonhos e projetos, se torna insignificante diante dos grandes planos a serem realizados. O homem está sempre em busca, tenta alcançar o inalcançável e acaba esquecendo o seu dia-a-dia. Essa é a ideologia que leva o sujeito moderno à cegueira, e esses valores transcendentes foram inventados por esse mesmo homem que agora perdeu o total domínio sobre eles. Tudo parece desconexo e as respostas até então criadas para dar sentido à vida, mostra o lado oposto da moeda, e se torna uma negação da mesma. No âmbito das novas descobertas científicas da modernidade, Pascal deixa claro esse sentimento de nadificação e chega a afirmar o pavor do ser humano diante do infinito que se abre: "Eis o que vejo e o que me perturba. Olho para todos os lados e por toda parte só vejo obscuridade. A natureza não me oferece nada que não seja objeto de dúvida e de inquietação" (PASCAL, 1979, p. 93). Ou seja, o sujeito moderno cria uma nova concepção de ordem universal, não mais ligada a uma ideia de Deus Criador e Organizador do universo, posto que a ciência reinterpreta essa ordem a partir de leis e experimentações empíricas. E as respostas encontradas pelo homem são ainda perturbadoras: o espaço é infinito, o cosmos é ilimitado, o ser humano é ínfimo diante de tais grandezas e percebe que quanto mais busca conhecer, pouco sabe, "o finito se aniquila na presença do infinito e torna-se um puro nada" (PASCAL, 1979, p. 94). Essa grandeza da natureza é assustadora e o homem tenta esgotar um conhecimento sobre o mundo que nunca chega ao fim. O cosmos é sobretudo caos, ou seja, um espaço em que não há mais a segurança do saber. Sobre esse sentimento diz Volpi:

\footnotetext{
No universo físico da cosmologia moderna, não lhe é dado mais viver, e sentir-se em casa, como no cosmo antigo e medieval. Agora o universo lhe parece estranho a seu destino individual. Assemelha-se a uma cela apertada em que sua alma se sente prisioneira ou a uma infinitude sem nome que a intranquiliza. Diante do silêncio eterno das estrelas e dos espaços infinitos que lhe são indiferentes, o homem está só consigo mesmo. Não tem pátria (VOLPI, 1999, p. 16).
}

Volpi descreve bem essa falta de sentido que Ferry afirma como o niilismo da modernidade. Todas as verdades construídas pelo racionalismo, pelo humanismo e por todas as formas de pensar da modernidade são fortes, porém, deixam o sujeito moderno perdido em meio a tudo aquilo que ele mesmo construiu. $O$ excesso de respostas parece nada responder uma vez que desvela diante do sujeito a pequenez e fragilidade de suas descobertas, fazendo-o sentir-se sempre como um estranho que habita também um lugar não conhecido.

No fundo, é o excesso de verdade que se entende como niilismo. Esse é o sentido dado ao termo por Nietzsche, segundo Luc Ferry. É por isso que até mesmo o humanismo, assim como os ideais religiosos são niilistas e "até mesmo o ateísmo militante das Luzes se mostra, se pensarmos cuidadosamente, tão ou mais niilista que a religião propriamente dita" (FERRY, 2012a, p. 183). O progresso, os Direitos 
do Homem e do Cidadão, a República, a Liberdade, a Ciência são as novas figuras do ideal que conservam essa estrutura da negação da vida porque coloca o homem sempre olhando para um além, ou, como aponta Habermas, de "um olhar orientado para o futuro" em que o "presente se tornou simplesmente transitório" (2000, p. 23). Desse modo, a estrutura do religioso, que é niilismo por excelência, ainda vigora no âmbito da laicidade moderna e a tentativa dos modernos de fugir à falta de sentido, se tornam falhas.

\section{A especificidade do niilismo na interpretação de Luc Ferry}

Uma vez que o niilismo, para Ferry, configura-se como essa perda de sentido, é importante perceber os três modos como ele se apresenta na modernidade. Primeiramente no âmbito teórico, que permite ao homem o conhecimento do mundo, não de uma maneira científica, mas existencial. Nesse momento Ferry faz uma análise da globalização e apresenta a desconstrução das tradições em nome da vida boemia, em que o boêmio é aquele que "deseja engendrar um mundo novo, criar obras absolutamente extraordinárias, originais, inéditas, e para isso é necessário que antes ele se desfaça de todas as heranças tradicionais" (FERRY, 2012a, p. 37). Numa análise teórica cabe também tratar da globalização liberal e da democracia, que ao destruir os tempos idos que freavam o consumo, permite ao homem se entregar totalmente a ele (FERRY, 2012a, p. 44), além de analisar a sacralização do homem acontecida a partir do casamento por amor. Nesse primeiro momento, Ferry mostra que as revoluções e transformações do pensamento acabam por se tornar um processo sem sujeito, sem sentido e nem finalidade. Esse processo, que por si é niilista, é assegurado pelo capitalismo e sua economia desenfreadamente competitiva, resultada dos movimentos republicanos e racionalistas da modernidade. "Pressionado pela concorrência globalizada, o movimento da história é a partir de agora alimentado, para não dizer impulsionado, sem a menor finalidade, pela simples lógica mecânica, automática, anônima e cega da simples competição global" (FERRY, 2012a, p. 55). A inovação acontece desprovida de finalidade e não há nisso uma preocupação de transformação do mundo, de dar maior liberdade ao homem ou fazê-lo se sentir melhor. É preciso inovar para sobreviver a um mundo globalizado, que diariamente apresenta ao homem novas tecnologias, e faz com que esse homem acredite ser necessário adquirir o novo, trocar seu aparelho celular, smartphones, tabletes, só porque um novo modelo acaba de ser lançado, com design moderno e uma memória maior. Essa situação atualiza aquele sentimento de Pascal de que "o finito se aniquila na presença do infinito e torna-se um puro nada" (PASCAL, 1979, p. 94). Ou seja, a inovação não tem fim, e sua tarefa é a de fazer com que o já dado, o já adquirido, se torne obsoleto, descartável, desnecessário. Nessa lógica, o homem não consegue encontrar jamais algo que lhe satisfaça. Diferentemente de Ferry, Vattimo chama esse acontecimento de modernidade ${ }^{11}$.

11 Essa concepção da modernidade como a efetivação dessa sociedade do progresso e da inovação pode ser entendida quando Vattimo aponta para o fato de ser a modernidade caracterizada "pela ideia da história do pensamento como uma 'iluminação' progressiva, que se desenvolve com base na apropriação e na reapropriação cada vez maus plena dos 'fundamentos', que frequentemente são pensados também como as 'origens', de modo que as revoluções teóricas e práticas da história ocidental de apresentam e se legitimam na maioria das vezes como “recuperações', renascimentos, retornos" (VATTIMO, 2002, p. VI). Desse modo, fica nítido que aquilo que 
Essa globalização, fundamentada no ideal capitalista de inovação, influencia também a política. A cada dia, a política parece sem horizonte: mudanças econômicas e educacionais desestruturadas, em que os políticos parecem forçar situações e promover mudanças simplesmente para entrarem nos anais da história como revolucionários. Obras inacabadas, projetos sem fundamentos, prática política desesperada. "A verdade é que estamos todos no mesmo barco, que esse barco avança a toda a velocidade sem bússola ou compasso, e que a questão de saber como retomar o controle ainda está, evidentemente, fora do alcance" (FERRY, 2012a, p. 57). Esse sentimento caracteriza a perda do sentido da história e também do controle sobre os acontecimentos desse processo desenfreado de inovação, até mesmo, por parte da impotência política diante de um mercado independente. "O mundo escapa estruturalmente por todos os lados à nossa inteligência e ao nosso controle" (FERRY, 2012a, p. 61), e isso, como se vê, acontece não somente na esfera do conhecimento e do desenvolvimento científico, como se viu na modernidade, mas também, no domínio da vida econômica, onde os mercados financeiros, como a política, parecem descontrolados e sem o comando de qualquer ser humano.

Segundo Ferry, a história de Frankenstein retrata de modo mitológico essa situação experimentada pelo homem moderno: a criatura escapa ao domínio do criador (FERRY, 2012a, p. 68). Acrescenta-se ainda: a criatura passa a dominar o criador. Esse episódio mostra o quanto o orgulho insensato do homem e sua arrogância em "se considerar Deus" (FERRY, 2012a, p. 68) leva à destruição. Uma destruição que não se restringe, como na história de Frankenstein, ao mundo físico: cidades arruinadas ou devastação planetária, mas, sobretudo, o homem vê sufocada sua própria liberdade. A liberdade criadora se vê dominada por aquilo que criou, torna-se ela mesma subserviente ao criado. Esse mito se torna ilustrativo nessa lógica do mundo globalizado e consumista: o que se tem é uma generalização do hiperconsumo somado a isso, uma impotência em relação à capacidade de prevenção e regulação de uma falência social, de crises e etc.

No âmbito moral, por sua vez, Ferry aponta para a existência de um "niilismo perfeito", aquele que, segundo Nietzsche, marca o pensamento do século XX. Esse niilismo, diferente de um pensamento comum acerca da temática, não é aquele da não defesa de valores, da falta de ideal ou da descrença total, ou seja, da negação. Do contrário, é aquilo que acima denominamos como excesso de ideais, aquele no qual o cristianismo oferece sua matriz fundamental e que se caracteriza por um excesso de afirmações. Ou seja, o niilismo perfeito resulta da ideologização da transcendência, algo que, segundo Ferry, Nietzsche rejeita com todas as forças:

O que ele rejeita com todas as forças é uma transcendência que, assumindo a forma de um 'ídolo', de um ideal oposto ao real, nega esse real e o declara ruim e, por isso mesmo, se opõe à possibilidade do amor fati, da vida boa que o idealismo remete falsamente a um futuro mais ou menos distante, a uma serenidade que viria mais tarde, quando estivermos no paraíso, quando se tiver feito a revolução, quando a ciência e seus progressos estiverem completos, quando os direitos do homem e a democracia estiverem solidamente instalados etc. Cristianismo, comunismo,

até então Ferry chamou niilismo, a saber, a concepção de progresso, de inovação e racionalidade, em Vattimo é sinônimo de modernidade. Para esse autor niilismo é algo distinto dessa concepção lucferriana.

FERREIRA, Douglas Willian. Da modernidade em Luc Ferry à pós-modernidade de Vattimo: as diferentes concepções de niilismo. Griot : Revista de Filosofia, Amargosa - BA, v.19, n.2, p.87-107, junho, 2019. 
cientificismo e progressismo sempre nos prometem um futuro melhor, mas, para Nietzsche, bem como para os sábios gregos, é aqui e agora que se tem de viver, e quando a transcendência toma a forma de um ídolo, de um ideal por vir, é exatamente a reconciliação com o real que ela nos impede de alcançar' (FERRY, 2012a, p. 200).

Portanto, o niilismo é essa atitude do homem de construir ídolos para si de tal modo que ele acaba subjugado por esse mesmo ídolo. $O$ fato de criar ídolos é já uma negação do presente, uma vez que enaltece as características daquilo que é ideologizado. Trata-se claramente de uma oposição ao real, uma fantasia, que aprisiona o sujeito num modo de vida distante, numa maneira utópica de lidar com o real. Essa transcendência esgota as possibilidades de amor à vida, amor fati, amor que permite ao homem se afirmar. Por vezes, a transcendência que é niilismo, leva essa própria realidade ao esquecimento. Esse niilismo perfeito sujeita o homem a uma situação de espera e não de prática. Tudo é lançado no futuro e o presente passa a estar inerte e preso num amontoado de ideais não concretizados. Mais que isso, essa situação de niilismo é também aquela de rebaixamento do presente, esse instante único em que se pode fazer algo, e mesmo, de difamação da vida. Ou, porque não, a situação de satisfação dos preguiçosos, daqueles que preferem se prender a ideais estabelecidos, herdados, a recriar sempre e novamente um modo de agir e habitar o mundo, de lutar por seus sonhos.

Numa terceira dimensão, no âmbito da espiritualidade, entende-se o niilismo em Ferry como verdades transcendentes. Nessa lógica, a vida eterna é niilista, e a transcendência, uma ilusão suprema. De modo que, o niilismo no âmbito da espiritualidade se apresenta na forma da salvação prometida pela religião, sobretudo, na forte conotação cristã que esse termo possui. A representação cristã do mundo, segundo Ferry, é uma negação da vida presente, uma vez que coloca o homem à espera de uma outra vida, a vida no Reino dos céus. Desse modo, a vida não é um fim em si mesma, mas um meio pelo qual o homem pode alcançar a salvação. Essas ilusões, segundo o filósofo francês, foram severamente denunciadas por Nietzsche, posto que burlam a verdadeira situação humana de mortais. Com isso, o sujeito prefere se apegar a tais respostas fantásticas do que aceitar a verdade de sua existência.

Novamente, Ferry se inspira em Nietzsche: quando Zaratustra desce da montanha, e adverte aos homens que lhe escute acerca da necessidade de se desfazer das ilusões celestes, ele diz:

Exorto-vos, meus irmãos, a permanecer fieis à terra e a não acreditar naqueles que vos falam de esperanças supraterrestres. São envenenadores, quer o saibam ou não. São menosprezadores da vida, moribundos que estão, por sua vez, envenenados, seres de quem a terra se encontra fadigada; vão-se por uma vez! Noutros tempos, blasfemar contra Deus era a maior das blasfémias; mas Deus morreu, e com ele morreram tais blasfêmias. Agora o mais espantoso é blasfemar da terra e ter em maior conta as entranhas do impenetrável do que o sentido da terra (NIETZSCHE, 2002, §3, p. 13-14).

O que chama atenção na fala de Zaratustra é sua denúncia aos ideais que obstruem o homem a valorizar aquilo que lhe é mais humano, apontado por ele como 
sendo o terreno. O termo aqui possui mais do que o significado de oposição ao celeste, ou divino, mas alude para a própria vida do homem, sua temporalidade, sua história, sua humanidade. Nesse sentido, blasfemar é afirmar a existência de uma realidade outra que só será alcançada através dos sacrifícios pessoais, que incluem sobretudo, o sacrifício das coisas que são caracteristicamente 'humanas, demasiado humanas'. Esse ódio à vida, muitas vezes pregado pela religião, denuncia a força do transcendente imposta ao homem, que através de suas leis e regras oprimem o instintivo, o que é tipicamente criativo. Deus é a força que arrebanha e, por assim o ser, deve ser blasfemado, para que o sentido da terra, da vida, das potencialidades humanas, possa ressurgir.

Nesse sentido, a valorização de um reino celeste é um modo de atribuir valor ao mundo a partir de uma perspectiva útil de dominação do homem, ou seja, quando a religião afirma que existe uma vida pós-morte, e também que a vida plena e feliz só é alcançada a partir do momento em que o homem se deixa subjugar pelos ditames religiosos, ela quer com isso, afirmar seu poder e domínio sobre o sujeito. Nessas condições, retirar-se da situação niilista é aceitar o fato de que "o sentido da existência humana não é, não deve ser, a busca da vida eterna" (FERRY, 2012b, p. 49), e aceitar "acima de tudo a finitude, a mortalidade como tal" (FERRY, 2012b, p. 51). Segundo Ferry, vale mais uma vida de mortal bem-sucedida do que aceitar uma vida de imortal fracassada, porque repleta de ausências e de negações incabíveis. $O$ homem deve aceitar a morte para assim, ocupar o lugar que lhe cabe no mundo (FERRY, 2012b, p. 52).

Por detrás de todas essas afirmações, pode-se concluir que para Ferry o cristianismo é niilismo na medida em que propõe uma "personalização da salvação" (FERRY, 2007, p. 78). Afinal, se o niilismo no âmbito espiritual, se caracteriza pelo excesso de verdade advinda de uma realidade distinta que é eterna, e se essa mesma realidade foi uma criação do cristianismo e embasa toda a sua dogmática soteriológica, então o cristianismo é, nesses termos, niilismo.

\footnotetext{
Em seu sentido mais profundo, o niilismo identifica-se com a atitude religiosa em si, ou seja, com a vontade de inventar a todo custo valores transcendentes, superiores à vida, em nome dos quais, em contrapartida, poderíamos enfim julgá-la, declará-la mais ou menos boa ou ruim, mais ou menos fracassada ou bem-sucedida, mais ou menos digna de salvação. Assim começa a culpabilidade, para não dizer, o Fracasso (FERRY, 2004, p. 69).
}

Ao invés de uma afirmação da vida, os valores transcendentes levam-na ao fracasso, porque estando a própria liberdade limitada, bem como a criatividade do homem, o que se tem é a estagnação cultural, e a inércia existencial. Desse modo, essa afirmação da transcendência faz com que o homem perca seu valor, por se perder numa busca pelo todo que ele não pode alcançar. Essa totalização que caracteriza a busca pela unidade, não fracassou somente no âmbito individual, mas na vida social como um todo, uma vez que o próprio "Ocidente vive uma situação explosiva, uma pluralização que parece irresistível, e que torna impossível conceber o mundo e a história segundo pontos de vista unitários" (VATTIMO, 1992, p. 12). A afirmação da transcendência é também niilista na medida em que resulta na 
absolutização que o homem faz de si esquecendo-se, consequentemente, de sua facticidade, da mudança, do devir que caracteriza a própria transformação da vida. Diante disso, a mudança se tornou árdua e o contingente despertava o medo. A segurança do necessário, dos valores morais e dos ideais ruíram com aquilo que é mais próprio da vida: a transformação. Assim, o homem suportava a vida, um suportar que é padecimento e tolerância. É aquilo que Nietzsche chama como a lógica do rebanho: seguimento exacerbado a leis, submissão excessiva ao absoluto, desvalorização da humanidade do homem frente ao forte desejo de perfeição. Essa é a lógica niilista. Nesse sentido, o formato da espiritualidade religiosa-cristã, que não se limita historicamente ao medievo, mas se estende inclusive à modernidade e seu ateísmo, evidencia mais uma vez aquilo que se denomina como ideal. "É a noção de ideal, e não deste ou daquele dos seus conteúdos, que apresenta dificuldades" (FERRY, 2004, p. 70). Esse foi o significado, que no início desse artigo, se deu à toda movimentação da modernidade como resultado da crença. $O$ niilista é um crente, que 'absolutiza e diviniza' os ideais que acredita veementemente verdadeiros. $O$ crente é um niilista, porque aceita algo como verdadeiro em si mesmo.

O niilista, segundo Nietzsche, era tudo, exceto um homem sem ideal. Pelo contrário, era alguém repleto de 'fortes conviç̧ões', de 'princípios superiores', altamente 'morais e transcendentes'. O niilista de Nietzsche é fundamentalmente, no sentido amplo e até mesmo leigo, um crente, alguém que tem fé em ideais, quaisquer que sejam: religiosos, metafísicos ou ateus, humanistas ou materialistas (FERRY, 2010, p. 36).

Por isso, o niilista, ou o crente, é incapaz de reconhecer a força criativa que há dentro dele, uma vez que se torna subserviente aos ditames de sua crença, dos ideais que ele defende, se necessário, com a própria vida. Foi por causa de tantos niilismos, no sentido que aqui Ferry dá ao termo, que as tantas guerras religiosas aconteceram e continuam a acontecer, e na mesma lógica, as guerras políticas e ideológicas continuam a ceifar vidas. Ser niilista comporta um risco de vida, um risco da própria vontade de vida que se vê assassinada pelos ideais superiores. Não obstante, cabe ao homem tomar o máximo de cuidado para evitar essa lógica niilista de dominação da vontade e da vida.

Dadas essas explicações, cabe aqui questionar que tipo de niilismo é esse afirmado por Ferry e justificado, segundo o autor, em Nietzsche? O niilismo não seria uma postura inversa? Teria Luc Ferry feito uma distorção na leitura de Nietzsche sobre o niilismo? Em muitos aspectos, Ferry parece ter adequado a concepção de niilismo de Nietzsche aos seus anseios de afirmação de uma vida feliz, de uma concepção de vida boa que caracteriza, segundo o filósofo, toda a trajetória da filosofia, desde a antiguidade até a contemporaneidade. Porém, Ferry não se distancia de Nietzsche. De fato, há em Nietzsche uma leitura de niilismo como esse exagero de certezas, de verdades e ideais. Mas esse é um dos aspectos do que Nietzsche caracterizou, em Fragmentos póstumos (2006), como "uma consequência da interpretação moral do mundo"( fragmento 7[43], p. 219), e que Deleuze em Nietzsche e a filosofia (1976) chamou niilismo negativo, porque se pauta na vontade de negar a vida em detrimento de verdades superiores (1976, p. 69). 
Desse modo, aqueles elementos que Ferry apontam como sendo niilistas, revolução, progresso, ciência, religião, direitos do homem e etc.-, o são, na medida em que buscam uma certa unidade e tornam o homem dependente de suas crenças, principalmente porque faz delas fator de organização e sistematização do mundo. No fundo, há um medo de que esses ideais que organizam, mesmo que às avessas, a vida do sujeito, deixem de responder aos acontecimentos cotidianos. Ou seja, a dependência psicológica de alguém, ou, nesse caso, de um ideal, que decida pelo sujeito e sustente suas ações, é no fundo, um sufocamento à capacidade desse sujeito. É o que também se pode chamar valor de nada ou vontade de nada, uma vez que as crenças nos valores absolutos tornam insignificante e vazia toda a vontade do homem (DELEUZE, 1976, p. 69).

O modo como Ferry apresenta sua leitura sobre o niilismo a partir de Nietzsche, faz com que Nietzsche seja visto unicamente como um crítico do niilismo, sem considerar o Nietzsche defensor do niilismo ativo. Isso se dá na medida em que Ferry identifica niilismo e verdades supra-humanas, no que resulta que a crítica ao transcendente é também uma crítica ao niilismo. O filósofo chega a afirmar: "Não sou nietzschiano, mas, em contrapartida, sempre tive a certeza de que é preciso aceitar a crítica nietzschiana do niilismo e dos ídolos porque, simplesmente, ela é profundamente justa" (FERRY, 2012a, p. 200). Contudo, em Nietzsche não se encontra somente uma crítica ao niilismo, ao niilismo passivo, como quer Ferry. Há, por outro lado, uma afirmação da necessidade de um niilismo ativo que torna o homem capaz de saber desse domínio dos ídolos. O problema de Nietzsche é que esses valores são considerados algo "em si”. Não se entende que eles foram criados por conta de necessidades pragmáticas do ser humano. Portanto, o problema não está nos valores como tais, mas em não se reconhecer sua origem humana, "demasiada humana". Tanto é assim que Nietzsche, o niilista ativo, tenta pensar novos valores. Contudo, esses valores tomam como critério a afirmação da vida, diferentemente daqueles que estruturados "em si" levam somente ao sufocamento.

\section{Considerações finais}

Vimos que há diversos modos de compreender o niilismo e coloca-lo como chave de leitura, tanto da modernidade, quanto da pós-modernidade. Nos autores aqui escolhidos, é visível a diferença de interpretação, não somente acerca do niilismo, mas sobretudo, do que se entende como modernidade. Enquanto que Ferry aponta o niilismo como característica da modernidade por ser ele a possibilidade de estruturação de novos valores, uma vez que o homem se encontra numa situação angustiante de falta de sentido, e, diante desse vazio, consegue retomar estruturas de sentido, Vattimo caracteriza a pós-modernidade como o momento niilista, por excelência, por ser o niilismo a garantia de significação da vida. É porque as estruturas metafísicas e violentas foram superadas, que o homem pós-moderno tem o mundo, a vida e a história como possibilidade aberta diante de si.

Contudo, para aproximar Vattimo e Ferry numa leitura convergente sobre niilismo e pós-modernidade, em que um diálogo harmonioso possa acontecer, é necessário ler também o niilismo ativo e não somente a crítica ao niilismo feita por Nietzsche. Nessa chave de leitura, talvez, seja possível associar o pensamento de 
ambos os autores. Essa questão, porém, deve ser a empreitada de uma nova pesquisa sobre Vattimo e Ferry e de uma possível leitura, de ambos, sobre a pós-modernidade. 


\section{Referências:}

FERRY, Luc. A revolução do amor, por uma espiritualidade laica. Rio de Janeiro: Objetiva, 2012a.

FERRY, Luc. Aprender a viver. Rio de Janeiro: Objetiva, 2007.

FERRY, Luc. O que é uma vida bem sucedida? Rio de Janeiro: DIFEL, 2004.

FERRY, Luc. Famílias, amo vocês, política e vida privada na época da globalização.

Rio de Janeiro: Objetiva, 2010.

FERRY, Luc. Vencer os medos, a filosofia como amor à sabedoria. São Paulo: Martins Fontes, 2008a.

FERRY, Luc; JERPHAGNON, Lucien. A tentação do cristianismo, de seita a civilização; Rio de Janeiro: Objetiva, 2012b

FERRY, Luc; GAUCHET, Marcel. Depois da Religião, o que será do homem depois que a religião deixar de ditar a lei? Rio de Janeiro: DIFEL, 2008 b.

VATTIMO, Gianni. Acreditar em acreditar. Lisboa: Relógio D’água, 1998.

VATTIMO, Gianni. Adeus à verdade. Petrópolis: Vozes, 2016.

VATTIMO, Gianni. A sociedade transparente. Lisboa: Relógio d'Água, 1992.

VATTIMO, Gianni. Depois da cristandade, por um cristianismo não religioso. Rio de Janeiro: Record, 2004.

VATTIMO, Gianni. Ética de la interpretación. Barcelona: Paidós, 1991.

VATTIMO, Gianni. O fim da modernidade, niilismo e hermenêutica na cultura pósmoderna.São Paulo: Martins Fontes, 2002.

VATTIMO, Gianni; RORTY, R.O Futuro da Religião - solidariedade, caridade e ironia. Rio de Janeiro: Relume Dumará, 2006.

DELEUZE, Gilles. Nietzsche e a Filosofia. Rio de Janeiro: Editora Rio, 1976.

ECO, Umberto; MARTINI, Carlo Maria. Em que creem os que não creem? Rio de Janeiro: Record, 2016. $18^{\mathrm{a}}$ ed.

HABERMAS, Jürgen. O discurso filosófico da modernidade. São Paulo: Martins Fontes, 2000.

HARVEY, David. Condição Pós-Moderna, Uma Pesquisa sobre as Origens da Mudança Cultural. São Paulo: Loyola, 1992.

HEGEL, Georg Wilhelm Friedrich. Fenomenologia do Espírito. Petrópolis, RJ: Vozes, 1992. $2^{\text {a }}$ ed.

NIETZSCHE, Friedrich. Assim Falava Zaratustra. 2002. Disponível em: $<w w w . e b o o k s b r a s i l . o r g / a d o b e e b o o k / z a r a . p d f>$. Acesso em: 15 maio 2017.

NIETZSCHE, Friedrich. Fragmentos póstumos. Madri: Tecnos, 2006.

PASCAL, Blaise. Pensamentos. São Paulo: Abril Cultural, 1979 (Coleção Os Pensadores).

ROCHA, Alessandro Rodrigues. Filosofia, Religião e Pós-modernidade: uma abordagem a partir de Gianni Vattimo. Campinas: Ideias e letras, 2013.

VOLPI, Franco. O niilismo. São Paulo: Loyola, 1999.

ZABALA, Santiago. Weakening Philosophy: Essays in Honour of Gianni Vattimo. Londres: McGill-Queen's University Press, 2007.

Autor(a) para correspondência: Douglas Willian Ferreira, Universidade Federal de Juiz de Fora, Rua José Lourenço Kelmer, s/n, São Pedro, 36036-900, Juiz de Fora - MG, Brasil. douglasinvictus@hotmail.com 